\title{
Identification of Bacterial Populations and Functional Mechanisms Potentially Involved in Biochar-Facilitated Antagonism of the Soilborne Pathogen Fusarium oxysporum
}

\author{
Barak Dror, ${ }^{1,2}$ Hildah Amutuhaire, ${ }^{1,2}$ Omer Frenkel, ${ }^{3}$ Edouard Jurkevitch, ${ }^{2}$ and Eddie Cytryn ${ }^{1, \dagger}$ \\ ${ }^{1}$ Institute of Soil, Water and Environmental Sciences, Volcani Institute, Agricultural Research Organization, Rishon-Lezion, Israel \\ ${ }^{2}$ Department of Plant Pathology and Microbiology, The Robert H. Smith Faculty of Agriculture, Food and Environment, The Hebrew \\ University of Jerusalem, Rehovot, Israel \\ ${ }^{3}$ Department of Plant Pathology, Volcani Institute, Agricultural Research Organization, Rishon-Lezion, Israel
}

Accepted for publication 31 January 2022.

\section{ABSTRACT}

Biochar soil amendment alleviates plant disease through microbial-mediated processes but drivers facilitating this "biochar effect" are not fully understood. In this study, cucumber plants were inoculated with and without the fungus Fusarium oxysporum f. sp. radicis-cucumerinum in either biocharamended or nonamended soils, and disease severity was assessed. Amplicon sequencing and shotgun metagenomics were then applied to identify bacteria and associated mechanisms potentially involved in pathogen inhibition, and candidate bacteria were tested for in vitro $F$. oxysporum f. sp. radiciscucumerinum-antagonizing capacity. Biochar-amended plants showed lower $F$. oxysporum f. sp. radicis-cucumerinum-associated growth stagnation compared with nonamended plants, supporting the biochar effect. Their rhizosphere had a more diverse microbiome with higher levels of secondary metabolite-encoding biosynthetic gene clusters (BGCs). Families Pseudonocardiaceae (Lentzea spp.) and Myxococcaceae were significantly more abundant in biochar-amended rhizospheres of $F$. oxysporum f. sp. radicis-cucumerinum-inoculated plants, and metagenomically assembled genomes (MAGs) from these taxa contained genes encoding enzymes involved in binding and degradation of chitin, and novel BGCs encoding secondary metabolites. Lentzea spp. isolates related to the above MAGs showed in vitro antagonistic activity against $F$. oxysporum f. sp. radicis-cucumerinum. Collectively, we postulate that biochar amendment generates a "buffering effect" that reduces $F$. oxysporum f. sp. radicis-cucumerinum-facilitated destabilization of the root-associated microbiome, maintaining beneficial taxa that produce antagonizing enzymes and secondary metabolites that sustain plant health.

Keywords: biochar, biocontrol, metagenomics, microbiome, NRPS, phyllosphere, plant-microbe interactions, plant pathology, rhizosphere, secondary metabolites
Organic amendments have been proposed as a means to control fungal and bacterial phytopathogens and reduce the use of chemical pesticides (Bonanomi et al. 2018). One promising organic amendment is biochar, produced by pyrolysis of organic materials, including crop residues, wood pruning waste, and manure. Supplementation of soil and plant growth media with biochar can enhance fertility and

\section{${ }^{\dagger}$ Corresponding author: E. Cytryn; eddie@volcani.agri.gov.il}

Funding: This work was supported by the United States-Israel Binational Agricultural Research and Development Fund grant number IS-5177-19F.

*The $e$-Xtra logo stands for "electronic extra" and indicates that five supplementary figures and supplementary tables are published online.

The author(s) declare no conflict of interest.

(C) 2022 The American Phytopathological Society increase plant productivity (Ding et al. 2016), as well as alleviate the burden of certain soilborne and foliar plant diseases (Bonanomi et al. 2018). This antagonistic capacity is presumably linked to different mechanisms, which include induction of systemic resistance in the host plant (Elad et al. 2010), modification of physicochemical soil characteristics (Agegnehu et al. 2016), and stimulation of diseasesuppressing root- and soil-associated microbiomes (Jaiswal et al. 2018). We previously determined that biochar-stimulated plant resistance to the foliar pathogen Botrytis cinerea and the soilborne pathogen Fusarium oxysporum f. sp. radices lycopersici is linked to increased microbial diversity, and enhanced carbohydrate and phenolic compound utilization in the rhizosphere microbiome (Jaiswal et al. 2017; Kolton et al. 2017).

The plant microbiome has a substantial impact on plant development, growth, and health (Berendsen et al. 2012; Trivedi et al. 2020). Specifically, plant-growth-promoting bacteria (PGPB) play important roles in plant health by either direct or indirect mechanisms, which 
include secretion of phytohormones and enzymes, nitrogen fixation, iron sequestering, and production of a wide diversity of secondary metabolites (SMs), among others (Vejan et al. 2016). Previous studies identified two primary mechanisms that facilitate antimicrobial activity by PGPB: the production of carbohydrate-metabolizing enzymes such as chitinases that digest chitin, the main component of fungal cell walls (Fernandes et al. 2016; Lacombe-Harvey et al. 2018; Nguyen et al. 2018), and the secretion of SMs with the ability to interfere with phytopathogens metabolic pathways (Coleman et al. 2011; Esmaeel et al. 2017). Nonribosomal peptides (NRPs) and polyketides (PKs) are SMs with a broad range of biological functions, including iron-scavenging (siderophores), communication, and antimicrobials (Newman and Cragg 2016). These metabolites are synthesized by nonribosomal peptide synthetase (NRPS) and polyketide synthase (PKS) megaenzymes (>500 kDa), which are encoded by operon-like biosynthetic gene clusters (BGCs), which contain several to dozens of genes. We previously demonstrated that soil and rhizosphere microbiomes harbor a diverse array of potentially novel SM-encoding BGCs, and that the composition of rhizosphere SMs is different than the adjacent bulk soil, suggesting that root-associated SMs play a role in bacteria-plant interactions (Dror et al. 2020).

To date, only a few studies have investigated the complex interactions between biochar, microbial communities, and plant health, and existing literature has primarily focused on single time points following biochar application, which does not enable assessment of temporal effects of biochar on pathogen progression relative to noninoculated plants. Although many studies have investigated the impact of biochar on microbial community structure, most do not include functional gene characterization (e.g., by using shotgun omics tools), thus preventing the establishment of potential mechanisms contributing to plant growth or pathogen suppression.

This study focused on identifying functional mechanisms underlying the "biochar effect" (i.e., pathogen inhibition facilitated by biochar amendment). We assessed the temporal impact of biochar amendment on $F$. oxysporum f. sp. radicis-cucumerinum, a devastating pathogen in cucurbit species, correlating plant performance or disease severity, bacterial community composition, and the presence of NRPS- and PKS-encoding genes. Moreover, we pinpointed specific bacterial candidates predicted to be involved in biochar-associated pathogen suppression by constructing metagenomically assembled genomes (MAGs). Within these recovered genomes, we focused on specific carbohydrate-active enzyme (CAZyme) families and BGCs encoding for SMs that potentially antagonize $F$. oxysporum.

\section{MATERIALS AND METHODS}

Experimental setup. Cucumber seeds (cultivar Manny, Genesis, Israel) were grown for 7 days in a temperature-controlled $\left(23^{\circ} \mathrm{C}\right)$ glasshouse in commercial nursery trays containing a previously characterized soil from Rehovot in central Israel (94\% sand, $2 \%$ silt, $4 \%$ clay, and $0.12 \%$ organic matter) (Klein et al. 2011), without or amended with $1 \%$ eucalyptus wood biochar prepared at $600^{\circ} \mathrm{C}$ (Good Energy, Israel). Subsequently, the germinated seedlings were transplanted into 10 -cm-diameter pots containing $1 \% \mathrm{~F}$. oxysporum f. sp. radicis-cucumerinum-inoculated or noninoculated soil, as previously described (Jaiswal et al. 2020). In total, 60 seedlings were planted in the following treatments (15 replicates/treatment): (i) noninoculated, nonamended soil; (ii) noninoculated, biochar-amended soil; (iii) $F$. oxysporum f. sp. radicis-cucumerinum-inoculated, nonamended soil; and (iv) F. oxysporum f. sp. radicis-cucumerinum-inoculated, biochar-amended soil. Plants were irrigated daily with tap water for 3 weeks.

Evaluation of disease incidence and symptoms. Three weeks after transplanting the seedlings, five plants were randomly selected from each treatment group and three morphological traits were measured to estimate the impact of biochar amendment and $F$. oxysporum f. $\mathrm{sp}$. radicis-cucumerinum inoculation on plant performance. Stem height (in centimeters) and central vein length in the first true leaf (in centimeters) were measured using a metal ruler, and dry weight (following overnight drying at $100^{\circ} \mathrm{C}$ ) was measured using an analytical scale. Plants were photographed and measured as described above, and the roots were immediately removed for subsequent processing and analyses as described below.

Root sampling and processing. Plants were gently agitated by hand to remove bulk soil and, subsequently, vigorously shaken to release attached rhizosphere soil. Rhizosphere and bulk soils were collected separately in sterile $50-\mathrm{ml}$ plastic tubes and stored at $-80^{\circ} \mathrm{C}$ until nucleic acid extraction. The stems of each plant $(F$. oxysporum f. sp. radicis-cucumerinum-inoculated and noninoculated) were also collected to validate the presence of $F$. oxysporum f. sp. radicis-cucumerinum in the stem tissue. Each stem was cut into three even pieces using sterile scissors, rinsed in a doubledistilled water-hypochlorite (50\%) mixture for $1 \mathrm{~min}$, placed on potato dextrose agar plates, and incubated at $27^{\circ} \mathrm{C}$ for 5 days.

Nucleic acid extraction, 16S ribosomal RNA gene sequencing, library preparation, and sequencing. DNA was extracted from bulk soil and cucumber roots using the DNeasy PowerSoil Kit (Qiagen), following the manufacturer's protocol, with $0.25 \mathrm{~g}$ of soil or rhizosphere as input material.

Microbial community structure was evaluated for all samples ( $n=3$ for bulk soil and $n=5$ for rhizosphere) by amplification of the hypervariable V4 region of the $16 \mathrm{~S}$ ribosomal RNA (rRNA) gene using universal bacterial primers $515 \mathrm{~F}$ and 806R, appended with the CS1 (forward) and CS2 (reverse) Fludigm adapters (Supplementary Table S1) (Green et al. 2015; Moonsamy et al. 2013). In addition, a subset of $10 \mathrm{~F}$. oxysporum $\mathrm{f}$. sp. radicis-cucumerinum-inoculated rhizosphere samples (5 biochar-amended and 5 nonamended) were subjected to shotgun metagenomic sequencing. Barcoded libraries for sequencing were prepared using a SWIFT 2S TURBO Kit (Swift Biosciences) and pooled sequenced using highoutput flow cells with paired-end $2 \times 150$ base reads on an Illumina NovaSeq sequencer. Library preparation and sequencing was performed at the University of Illinois at Chicago Sequencing Core.

All datasets have been deposited in the NCBI Short Read Archive under Bioproject PRJNA746716.

Bioinformatic pipeline. 16S rRNA gene amplicon sequencing. Amplicons were demultiplexed, preprocessed, and analyzed using QIIME2 (v2019.07) and the DADA2 denoising pipeline (Supplementary Table S2) (Bolyen et al. 2019). Low-quality bases (13 bp) were trimmed from the start of the sequence. Resulting exact sequence variants (ESVs) were taxonomically assigned using qiime2 q2-feature-classifier with Silva 138 (Pruesse et al. 2012). Chloroplast and mitochondrial 16S rRNA sequences, as well as ESVs represented by fewer than three sequences, were removed from downstream analyses. Raw and CSS-normalized count tables were used for downstream analyses and visualization using custom Python and R scripts.

Shotgun metagenome. Raw Illumina paired-end reads were quality filtered and evaluated by FASTQC software. Adaptors and lowquality bases were removed using Trimmomatic (Bolger et al. 2014) with customized parameters set to HEADCROP:10 SLIDINGWINDOW:4:20 MINLEN:110. Overall, following QC, 20 to 33 million paired-end DNA sequences were generated per sample (Supplementary Table S3). F. oxysporum f. sp. radicis-cucumerinum sequences were removed by comparing reads to a representative $F$. oxysporum f. sp. radicis-cucumerinum genome (GenBank GCA_ 001702695.2) with bowtie 2 and, subsequently, removing the reads with SAMtools (Langmead and Salzberg 2012). Quality-filtered 
DNA reads from all replicates $(n=5)$ were pooled together by treatment (nonamended and biochar-amended) and de novo assembled with metaSPAdes, using -meta flag (Nurk et al. 2017). Assembly quality was assessed using metaQUAST (Mikheenko et al. 2016). The assembly yielded 1,242,928 and 1,380,632 contigs $>500 \mathrm{bp}$ for the nonamended and biochar-amended samples, respectively. Contigs from each treatment were pooled together and gene prediction was performed using Prodigal in metagenome mode (Hyatt et al. 2010). Predicted genes from all samples (biochar-amended and nonamended) were combined and filtered ( $>80 \mathrm{bp}$ ), yielding 21,108,533 genes. These were used as input to create a nonredundant gene catalog generated using CD-HIT (based on 97\% similarity) (Li and Godzik 2006). The resulting gene catalog (with 17,987,130 genes) was aligned to the NCBI nonredundant protein database using Diamond with default parameters and sensitive mode (Buchfink et al. 2014). Sequence annotation to taxonomy and function (using Eggnog) were achieved with lowest-common ancestor using MEGAN V6 Ultimate Edition. To generate count data (number of mapped reads per gene), QC reads were aligned to the annotated gene catalog by bowtie2, CSS normalized, and used for downstream analyses using custom Python and R scripts.

Identification of SM-encoding genes. To identify and characterize SM-encoding BGCs in shotgun-metagenomes, we applied two approaches. First, assembled contigs from each treatment (biochar-amended versus nonamended) were filtered to include only sequences $>5,000 \mathrm{bp}$. These contigs were then used as input for BGC identification using a standalone, command-line version of antiSMASH (v.5.1.0, in -cb-general -cb-subclusters -pfam2go -genefinding-tool prodigal-m mode) (Blin et al. 2019). Custom Python scripts were then used to group GenBank files into specific BGC classifications, and taxonomy of bacteria harboring the BGCs was assigned by aligning contigs to the NCBI nonredundant database as detailed above. To get a better understanding of each identified BGC novelty and relationship with other known and predicted BGCs, individual antiSMASH-identified BGCs were used as input for the tools BiG-SCAPE and BiG-FAM, generating gene cluster family per inputted BGC (Kautsar et al. 2021; Navarro-Muñoz et al. 2020). Sequence identity network visualization was generated using Cytoscape 3.8 (https://cytoscape.org/). Subsequently, genes encoding for NRPSs and PKSs were identified using a pipeline previously developed in our lab (Dror et al. 2020). Briefly, the generated gene catalog described above was aligned against a custom database containing NRPS- and PKS-associated genes, extracted from the MIBiG repository (Kautsar et al. 2020) using Diamond (e-value $<10^{-40}$, coverage $>50 \%$, identity $>50 \%$ ). Resulting hits were merged with count tables and taxonomy annotations as described above, and further analyzed using custom Python scripts. Differential abundance of identified NRPSs and PKSs in biochar versus nonamended samples was determined using the R DESeq 2 package, using raw count tables. To identify and analyze complete or near-complete BGCs, hits (NRPS- and PKS-identified open reading frames [ORFs]) were mapped each to its containing assembled contig using custom Python scripts, based on their corresponding unique IDs.

MAG binning and functional analysis. MAGs were binned based on contigs from either biochar-associated samples or nonamended samples using MetaBat2 (Kang et al. 2019) and CONCOCT (Alneberg et al. 2013). Predicted bins from each binner were further analyzed and quality filtered using DAS Tool metabinner default settings (Sieber et al. 2018) to generate best bins. Bins from this final step were assessed (completeness and contamination) using CheckM (lineage_wf workflow, v1.1.2) (Parks et al. 2015) and their taxonomy was assigned using the GTDB-Tk classify_wf workflow (Chaumeil et al. 2020). ORFs of assembled MAGs were predicted using Prodigal and annotated to the nr database with Diamond (as described above). These ORFs were used as input for GhostKoala, in order to predict Kyoto Encyclopedia of Genes and Genomes-defined metabolic pathways (Kanehisa et al. 2016), and for dbCAN2 web-server (v9.0) to annotate CAZymes (Zhang et al. 2018). Within the dbCAN2 framework, only hits that were found with both Diamond (e-value $<1 \mathrm{e}^{-102}$ ) and HMMER (e-value $<$ $1 \mathrm{e}^{-15}$, coverage $>0.35$ ) were further analyzed.

Real-time quantitative PCR of $F$. oxysporum $f$. sp. radiciscucumerinum. Real-time quantitative PCR (RT-qPCR) was used for the quantification of $F$. oxysporum $\mathrm{f}$. sp. radicis-cucumerinum in 3-week-old rhizosphere DNA samples, as previously demonstrated (Klein et al. 2013). Briefly, we used the FORC-F5 and FORC-R2 primer set (Supplementary Table S1), and 10-fold dilutions of F. oxysporum f. sp. radicis-cucumerinum DNA were used as absolute quantitative standards. Melting curve analysis and agarose gel electrophoresis were conducted to confirm the specificity of the amplification.

In vitro antifungal assays. Dry-powdered bacterial strains (Supplementary Table S4) were ordered from the Leibnitz Institute German Collection of Microorganisms and Cell Cultures GmbH (DSMZ) (https://www.dsmz.de/), grown in manufacturer-recommended media (GYM), and tested for antifungal activity against $F$. oxysporum f. sp. radicis-cucumerinum, as described below. Escherichia coli ATCC 25922 and Luria-Bertani-GYM medium were used as negative controls. The antifungal activity of individual strains was tested using a fluorescence-based method. In this method, cell-free supernatant (CFN) was prepared from each bacterial strain from a 7-day-old culture grown at $28^{\circ} \mathrm{C}(\mathrm{GYM}$ media, $160 \mathrm{rpm})$. The inoculum was centrifuged $(5,000 \times g$ for $10 \mathrm{~min})$, and the resulting supernatant was filtered by using a $0.45-\mu \mathrm{m}$ Millex-HV syringe filter (Sigma-Aldrich, Israel). CFN $(100 \mu \mathrm{l})$ from each bacterial candidate was then added to $100 \mu \mathrm{l}$ of green fluorescent protein (GFP)-labeled $F$. oxysporum $\mathrm{f}$. sp. radicis-cucumerinum (contributed by the Prof. Shay Covo lab, HUJI, Israel) in a sterile. 96-well black-bottom plate and incubated for $36 \mathrm{~h}\left(160 \mathrm{rpm}, 25^{\circ} \mathrm{C}\right)$. Following incubation, the fluorescence emitted from each well was read by using a Synergy Neo 2 Hybrid Multi Reader (BioTek) at 485 and $510 \mathrm{~nm}$ (excitation and emission wavelengths, respectively).

Statistical analysis. Significant differences in plant morphological traits were measured by multiple comparisons of the means using the Tukey-Kramer honestly significant difference (HSD) test $(\alpha=0.05)$. $\alpha$-Diversity (Shannon, Fisher, and Faith-PD) and $\beta$-diversity (Aitchison distance, the Euclidean distance between samples after clr transformation) indices for the rhizosphere microbial communities were calculated with the Vegan $\mathrm{R}$ package. The adonis function (analysis of variance using distance matrices) was used to compare the microbial communities as a function of different growth stages and specific amendments, including stage-amendment interaction (with 10,000 permutations). Differential abundance between treatments was calculated with the DEseq2 and Maaslin2 R packages, using default settings (Love et al. 2014; Mallick et al. 2021). Only hits that were determined as significantly different by both methods (false discovery rate $<0.05$ ) were selected for downstream analyses. Antifungal assays mean, distributions, and analysis of variance statistical tests were calculated using R. All generated $P$ values were corrected for multiple comparison by the Benjamini-Hochberg procedure.

\section{RESULTS}

Effect of biochar amendment on $F$. oxysporum f. sp. radiciscucumerinum-facilitated plant growth inhibition. Cucumber plants were inoculated with and without $F$. oxysporum f. sp. radiciscucumerinum and grown for 21 days in either biochar-amended or 
nonamended soils. Although no difference in plant growth was observed between noninoculated plants regardless of amendment, biochar-amended plants showed significantly lower $F$. oxysporum $\mathrm{f}$. sp. radicis-cucumerinum-associated growth stagnation compared with non-amended plants, as demonstrated by stem height $(P$ value $<0.01$, Wilcoxon signed-ranks test) (Fig. 1; Supplementary Fig. S1). F. oxysporum f. sp. radicis-cucumerinum-inoculated, biochar-amended plant height averaged $6.3 \mathrm{~cm}$ compared with $4.6 \mathrm{~cm}$ for the nonamended plants, with only a 13 versus $37 \%$ growth reduction compared with noninoculated plants, respectively. Moreover, biochar-amended plants had lower concentrations of $F$. oxysporum f. sp. radicis-cucumerinum in the rhizosphere as determined by RT-PCR quantification (Supplementary Fig. S2).

We compared the bacterial community diversity of biocharamended and nonamended samples in bulk soils prior to sowing (7 days after biochar amendment), in 7-day-old seedlings (postsowing), and in mature 3-week-old plant roots with and without $F$. oxysporum f. sp. radicis-cucumerinum inoculation. No difference in $\alpha$ diversity (Shannon and Faith-PD indices) was observed between nonamended and biochar-amended treatments in soil, seedling rhizosphere, and the rhizosphere of noninoculated mature plants. However, in the $F$. oxysporum f. sp. radicis-cucumerinum-inoculated treatments, the $\alpha$ diversity of the rhizosphere microbiome of nonamended plants was significantly lower than the biochar-amended plants. The latter was similar to that of noninoculated plants (Fig. 2A, Shannon, $P$ value $<0.05$, Tukey's HSD test) (Supplementary Fig. S3A, Faith-PD), suggesting that $F$. oxysporum f. sp. radiciscucumerinum facilitates a reduction in bacterial diversity, which is alleviated in the presence of biochar. Correspondingly, in nonamended treatments, inoculation with $F$. oxysporum f. sp. radiciscucumerinum resulted in a shift in the rhizosphere bacterial community composition at both the family (Fig. 2B, adonis $P$ value $<0.01$ for $F$. oxysporum f. sp. radicis-cucumerinum-inoculated samples) and ESV (Supplementary Fig. S3B, adonis $P$ value $<0.01$ for $F$. oxysporum $\mathrm{f}$. sp. radicis-cucumerinum-inoculated samples) levels but, in biochar-amended pots, the observed $\beta$ diversity was much closer to that of the noninoculated samples.

Taxonomical characterization. We further characterized the taxonomic affiliation and relative abundance of the bacterial communities in the rhizosphere of the biochar-amended and nonamended samples inoculated with $F$. oxysporum f. sp. radicis-cucumerinum using DESeq2 and MAaslin2. The relative abundance of nine bacterial

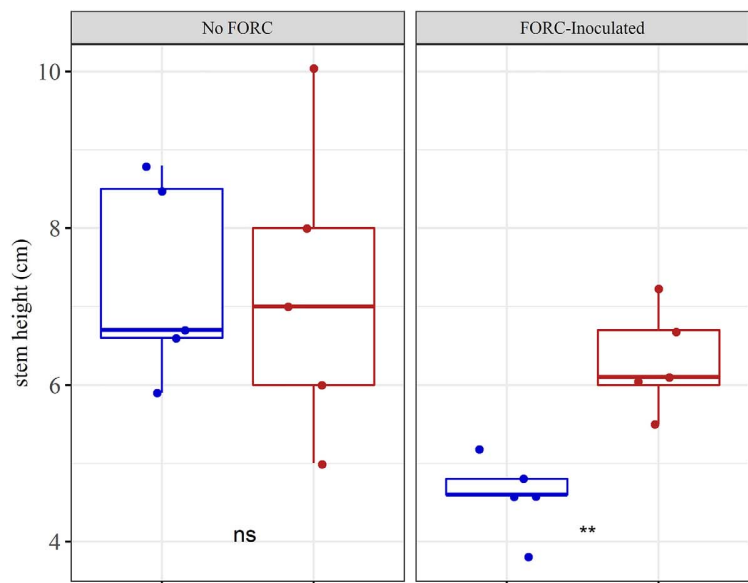

amendment E우 none E\% biochar

Fig. 1. Stem height (in centimeters) of noninoculated and Fusarium oxysporum f. sp. radicis-cucumerinum (FORC)-inoculated cucumber plants grown in nonamended and biochar-amended soils. Asterisks $(* *)$ indicate $P$ value $<0.01$ and NS $=$ not significant (Tukey's honestly significant difference, $n=5$ ). families was significantly higher ( $\log _{2}$-fold change $[\mathrm{FC}]>2$, corrected $P$ value $<0.05)$ in the biochar-amended samples, and one family was significantly more abundant in the nonamended samples (Fig. 3). Of note, the Actinobacteria family Pseudonocardiaceae $\left(\log _{2} \mathrm{FC}>5\right)$ and one uncharacterized family (belonging to the order Solirubrobacterales $\left.\left[\log _{2} \mathrm{FC}>5\right]\right)$, as well as one uncharacterized Deltaproteobacteria family from the order Myxococcales $\left(\log _{2} \mathrm{FC}>4.5\right)$, were significantly more abundant in biochar-amended rhizosphere. In nonamended rhizosphere samples, we found the Gammaprotoebacteria family Xanthomonadaceae $\left(\log _{2} \mathrm{FC}>3\right)$ to be significantly enriched.

Characterization and taxonomic affiliation of SM-encoding genes. Analysis of assembled contigs ( $>5,000 \mathrm{bp})$ using antiSMASH revealed a higher relative abundance of NRPS and type I PKS (T1PKS) BGCs in the biochar-amended samples compared
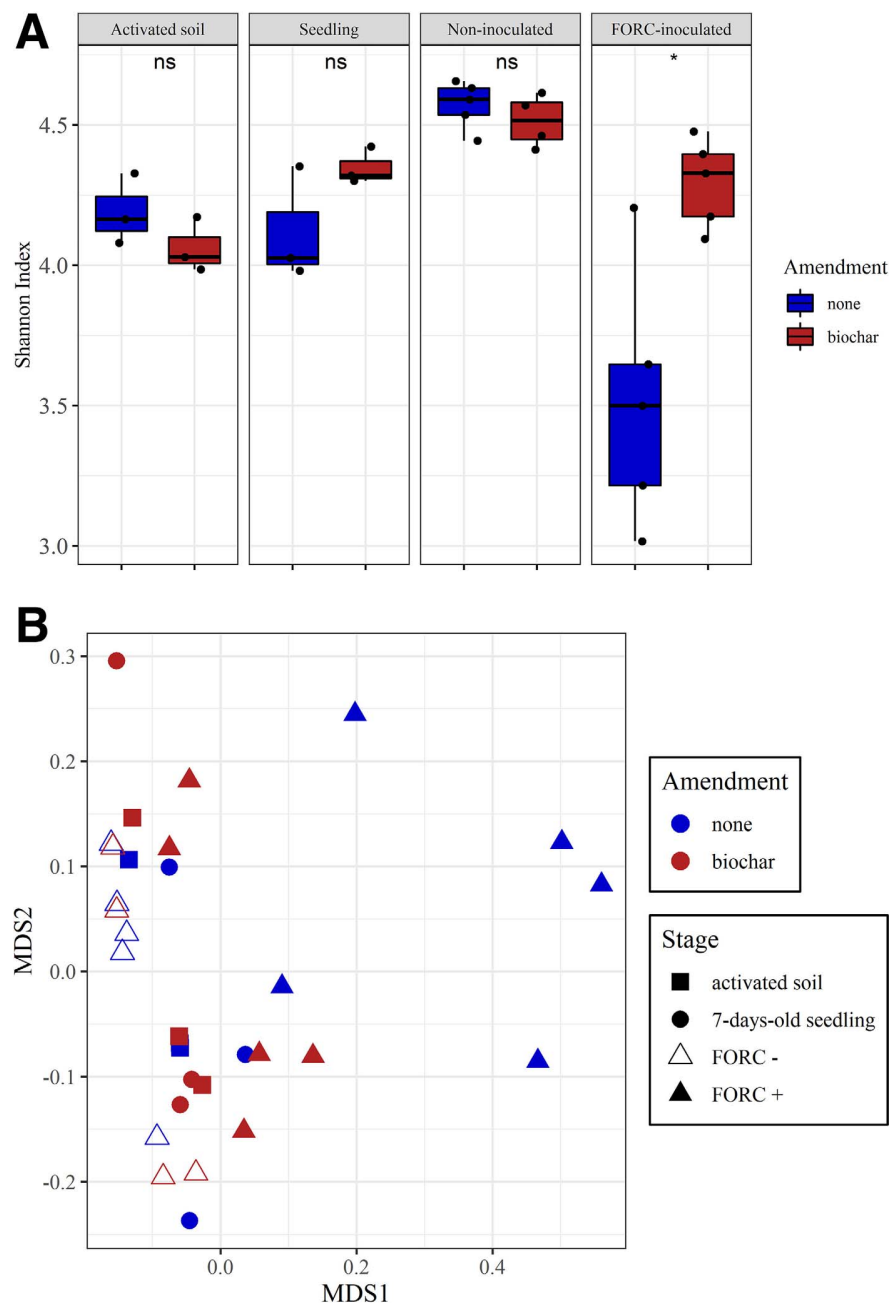

Fig. 2. A, Shannon diversity of cucumber rhizosphere bacterial communities grown in nonamended and biochar-amended soils, with or without Fusarium oxysporum f. sp. radicis-cucumerinum (FORC). An asterisk $\left(^{*}\right)$ indicates $P$ value $<0.05$ and $N S=$ not significant (Tukey's honestly significant difference test, $n=5$ ). B, Nonmetric multidimensional scaling (NMDS) using Aitchison dissimilarity at the family level, based on $16 \mathrm{~S}$ ribosomal RNA gene sequencing. According to permutational multivariate analysis of variance, plant stage explained $34 \%$ of the rhizosphere microbiome structure (adonis test $P$ value $<0.05, R^{2}=0.34$ ) and amendment an additional $5 \%$ (adonis test $P$ value $<0.05, R^{2}=0.047$ ), while stage-amendment interaction were insignificant $(P$ value $=0.077)$. Within the $F$. oxysporum f. sp. radicis-cucumerinum-inoculated samples, biochar-amended samples were significantly different compared with nonamended samples ( $P$ value $<0.01$, adonis method $)$. 
with the nonamended ones (approximately 37 and 9.5\% versus approximately 29 and 4.4\%, respectively) (Supplementary Fig. S4). Phylogenetic analysis of BGCs revealed specific taxa in the biochar-amended rhizosphere samples. Pseudonocardiaceae- and Myxococcaceae-associated BGCs were only present in the biocharamended samples (Fig. 4A, outer panel), correlating with the taxonomic analysis described above. Specifically, five Pseudonocardiaceae- and eight Myxococcales-associated NRP-encoding BGCs were identified. T1PKS-encoding BGCs were numerous in Pseudonocardiaceae genomes (10 out of $31 \mathrm{BGCs})$, whereas terpene- and bacteriocin-encoding BGCs were abundant in the Myxococcales genomes (5 of each type out of 33 BGCs) (Fig. 4B, inner panel). At the class level, BGCs belonging to Bacilli, Verrucomicrobia, Bacteroidetes, Flavobacteria, and Chitinophagia were only found in the nonamended samples, and Deltaproteobacteria- and Actinobacteria-associated contigs only identified in the biochar-amended samples (Supplementary Fig. S5).

Given the pivotal role of NRPS and PKS in bacteria-bacteria and bacteria-plant interactions, we further focused on NRPS- and PKS-associated BGCs by annotating predicted ORFs from the shotgun metagenomic samples against a custom database of core NRPS and PKS domains (extracted from the MIBiG repository) (Kautsar et al. 2020). The diversity of these domains in the biochar-amended rhizosphere samples was significantly higher (Fig. 5A, $P$ value $<0.05$ ) and more uniform (Fig. 5B, $R=0.46, P$ value $<0.01$ for biochar-amended versus nonamended soils) than in the rhizosphere of the nonamended samples.

MAGs from biochar-amended, $F$. oxysporum f. sp. radiciscucumerinum-suppressive samples. To pinpoint specific rhizosphereassociated bacteria and identify associated mechanisms potentially involved in the observed $F$. oxysporum f. sp. radicis-cucumerinum suppression, we binned assembled contigs from the biocharamended samples into MAGs. Application of the DAS Tool generated 11 high-quality MAGs (score > 0.6) (Table 1) that were taxonomically classified using the GTDB-Tk toolkit. Among identified MAGs, two were identified to the genus level as Lentzea spp. (MAG2) and Haliangium spp. (MAG15) belonging to the Pseudonocardiaceae and Kofleriaceae (Myxococcales) families, respectively. Two were identified to the family level as uncharacterized Polyangiaceae spp. (Myxococcales, MAG5) and Cytophagaceae spp. (Cytophagales, MAG6). As described above, Pseudonocardiaceae, Myxococcales, and Cytophagales were all highly enriched in the biochar-amended samples, and the first two were rich in SM-encoding BGCs.

To further identify potential fungal-antagonizing characteristics, we mapped each MAG against the CAZyme family database (CAZy) and against antiSMASH to identify SM-associated BGCs. The CAZyme profile of the four MAGs revealed an extensive array of glycoside hydrolases $(\mathrm{GH})$, carbohydrate-binding modules (CBMs), and glycosyl transferases (GTs) (Fig. 6A). These included enzyme families involved in binding and degradation of carbohydrates such as chitin, xylan, and cellulose (i.e., CBM-2, CMB-4, and CBM-13; GT-2 and GT-35; and GH18), known to mediate bacteria-fungus and bacteria-plant interactions (Fig. 6B). MAG2 (Lentzea spp.) also contained the auxiliary activity families AA10 and AA3_2 involved in the degradation of chitin and lignin (Fig. 6B). We found 58, 39, 22, and 23 SM-associated BGCs within MAG2, MAG15, MAG5, and MAG6, respectively, with several NRPS- and PKS-encoding BGCs in all MAGs, especially in MAG2 (Fig. 7). The MAG5 and MAG6 BGCs did not encode known products based on antiSMASH

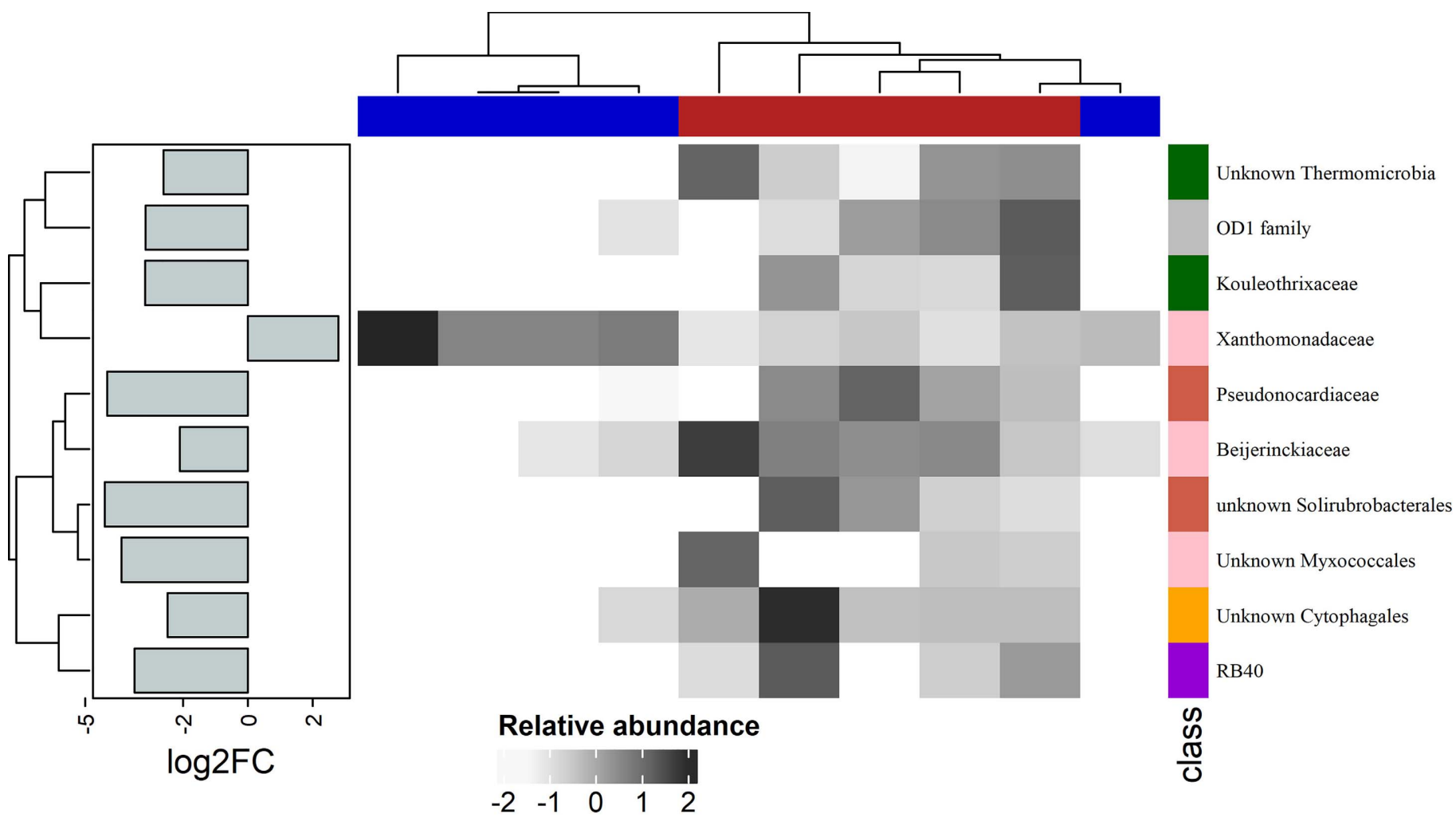

Fig. 3. Relative abundance (normalized) and $\log _{2}$ fold-change $\left(\log _{2} \mathrm{FC}\right)$ of significantly abundant bacterial families in biochar-amended (red) and nonamended Fusarium oxysporum f. sp. radicis-cucumerinum-inoculated (blue) cucumber plants. Families are shown on the right side and associated classes are indicated by colored boxes to their left (green $=$ Chloroflexi, gray $=$ Parcubacteria, pink $=$ Proteobacteria, red $=$ Actinobacteria, and orange $=$ Bacteroidetes). Only bacterial taxa with an adjusted $P$ value $<0.05$ (following Benjamini-Hochberg correction) and log ${ }_{2} \mathrm{FC}>2$ were included. $\log _{2} \mathrm{FC}$ relates to the effect size estimate of reported family between biochar-amended and nonamended samples, reported on a logarithmic scale to base 2. Abundance is based on analysis of $16 \mathrm{~S}$ ribosomal RNA gene amplicon sequences. 


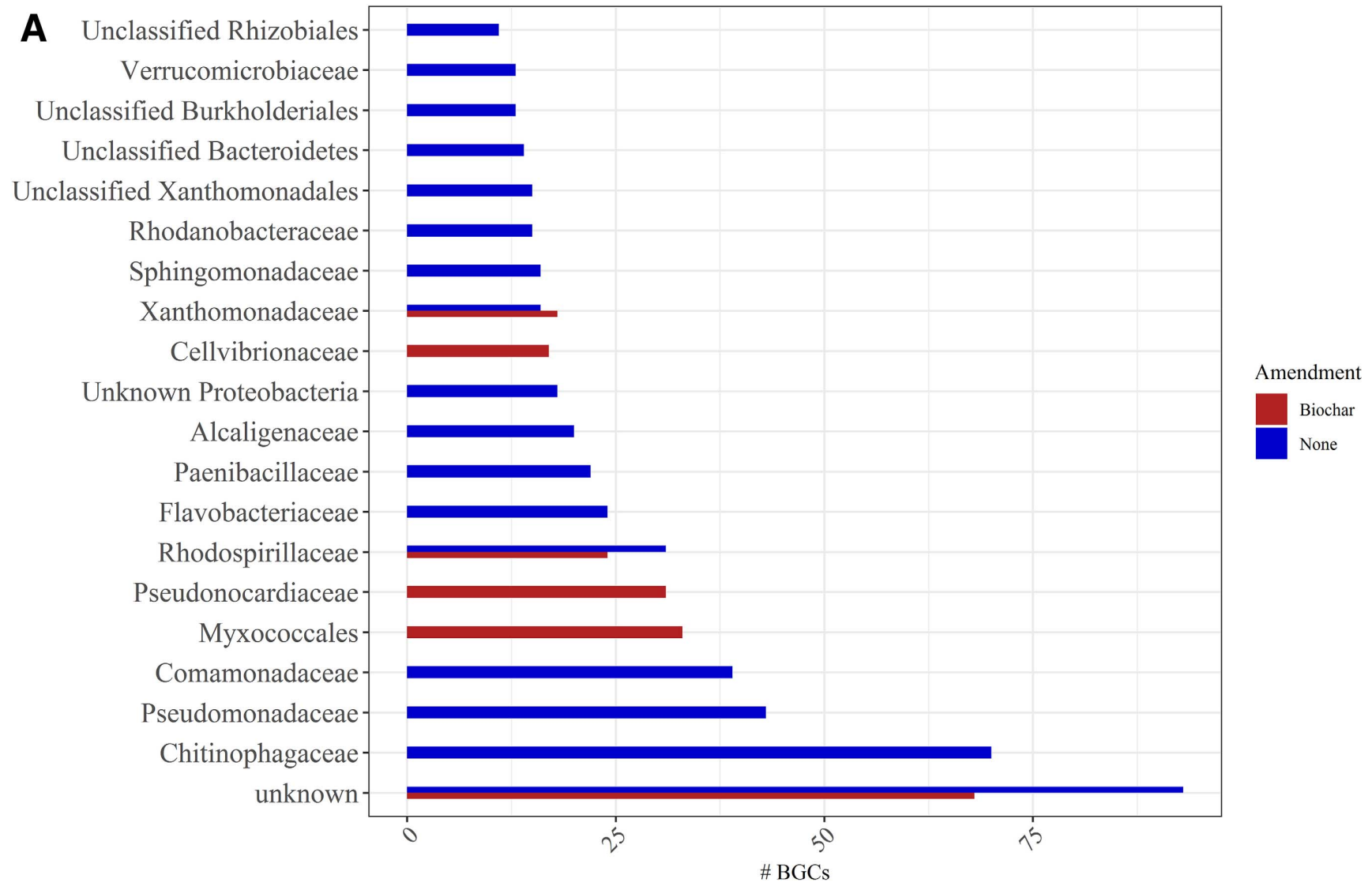

B
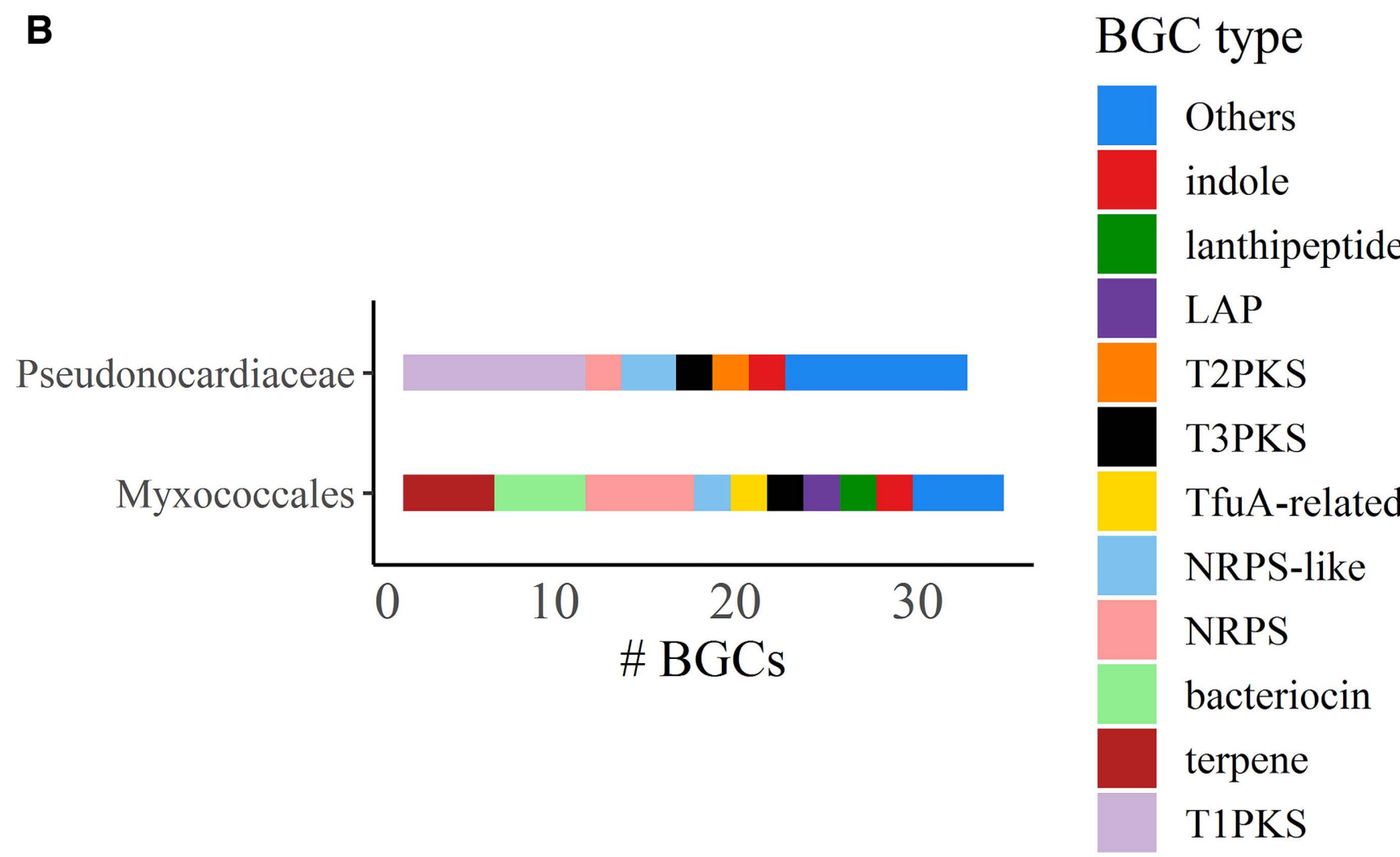

Fig. 4. A, Family-level taxonomy of secondary metabolite-synthesizing biosynthetic gene clusters (BGCs) (identified by antiSMASH) in nonamended and biochar-amended Fusarium oxysporum f. sp. radicis-cucumerinum-inoculated cucumber samples, based on shotgun metagenome contigs. B, Distribution of BGC types associated with Pseudonocardiaceae and Myxococcales groups, which were found only in biocharamended samples. Only contigs $>5,000$ bp were used as input. PKS $=$ polyketide synthase and NRPS $=$ nonribosomal peptide synthetase. 
predictions ( $>90 \%$ identity). In contrast, MAG2 contained three BGCs that were $100 \%$ identical to clusters encoding for the bicyclic terpene geosmin, found in several species of the order Actinomycetes and MAG15 contained four BGCs that were $100 \%$ identical to known clusters (two geosmin, one carotenoid, and one NRPS-like VEPE/ AEPE/TG-1) Supplementary Table S5).

Given the high number of SM-associated BGCs identified by antiSMASH within the MAG2 genome, we tested the capacity of CFN of four isolates (Lentzea flaviverrucosa strain 44664, L. albida strain 44437, L. nigeriaca strain 45680, and L. deserti strain 45480) obtained from the DSMZ bacterial collection to suppress $F$. oxysporum f. sp. radicis-cucumerinum growth by using a fluorescentbased assay. The CFN of isolates 44664 and 44437 significantly inhibited (Student's $t$ test, $P<0.01$ ) GFP-labeled $F$. oxysporum $\mathrm{f}$. sp. radicis-cucumerinum spores following $36 \mathrm{~h}$ of incubation (80 and 70\%, respectively) (Fig. 8), as compared with both the negative control E. coli ATCC 25922 and GYM media (-5 and 40\%, respectively). In contrast, no significant inhibition was observed for isolates 45680 and 45081 .

\section{DISCUSSION}

Biochar has been applied in agriculture for at least five millennia, and several studies from the last decade indicate that it facilitates suppression of diseases caused by both foliar and soilborne pathogens (Chen et al. 2020; Huang et al. 2015; Kolton et al. 2017; Wang et al. 2019). However, the mechanisms responsible for this observed biochar effect are not well understood. The objective of
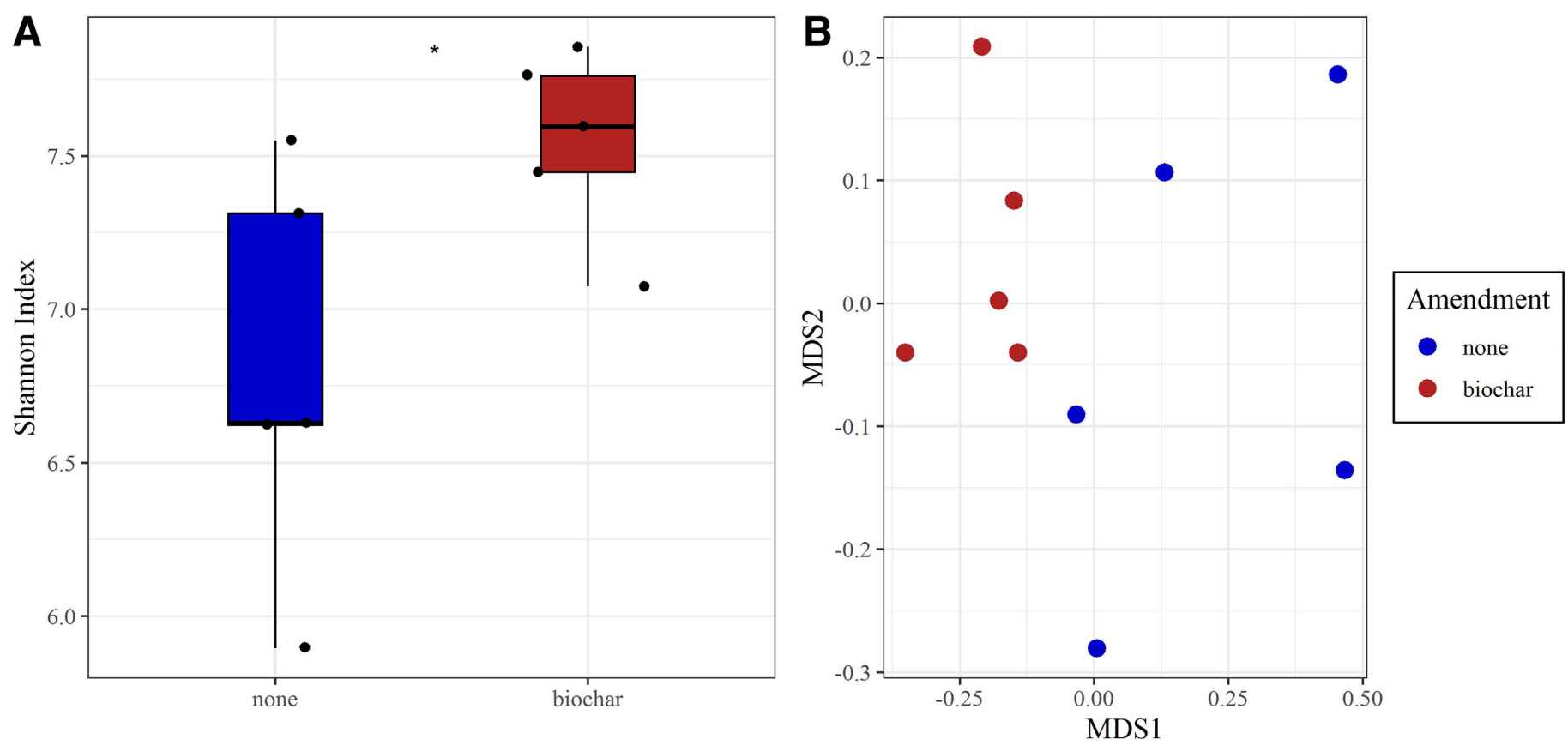

Fig. 5. A, Shannon diversity of nonribosomal peptide synthetase (NRPS) and polyketide synthase (PKS) core genes found in Fusarium oxysporum f. sp. radicis-cucumerinum-inoculated samples grown in nonamended and biochar-amended soils. Asterisks $(* *)$ indicate $P$ value $<0.01$ and NS $=$ not significant (Tukey's honestly significant difference, $n=5$ ). B, Nonmetric multidimensional scaling (MDS) using Aitchison dissimilarity of NRPS and PKS core genes found in studied samples. Adonis $P$ value $<0.01$ for biochar-amended versus nonamended samples.

TABLE 1

Descriptive summary of high-quality metagenomically assembled genomes (MAGs) generated from shotgun metagenomic reads of Fusarium oxysporum f. sp. radicis-cucumerinum-inoculated, biochar-amended rhizosphere samples ${ }^{\mathrm{a}}$

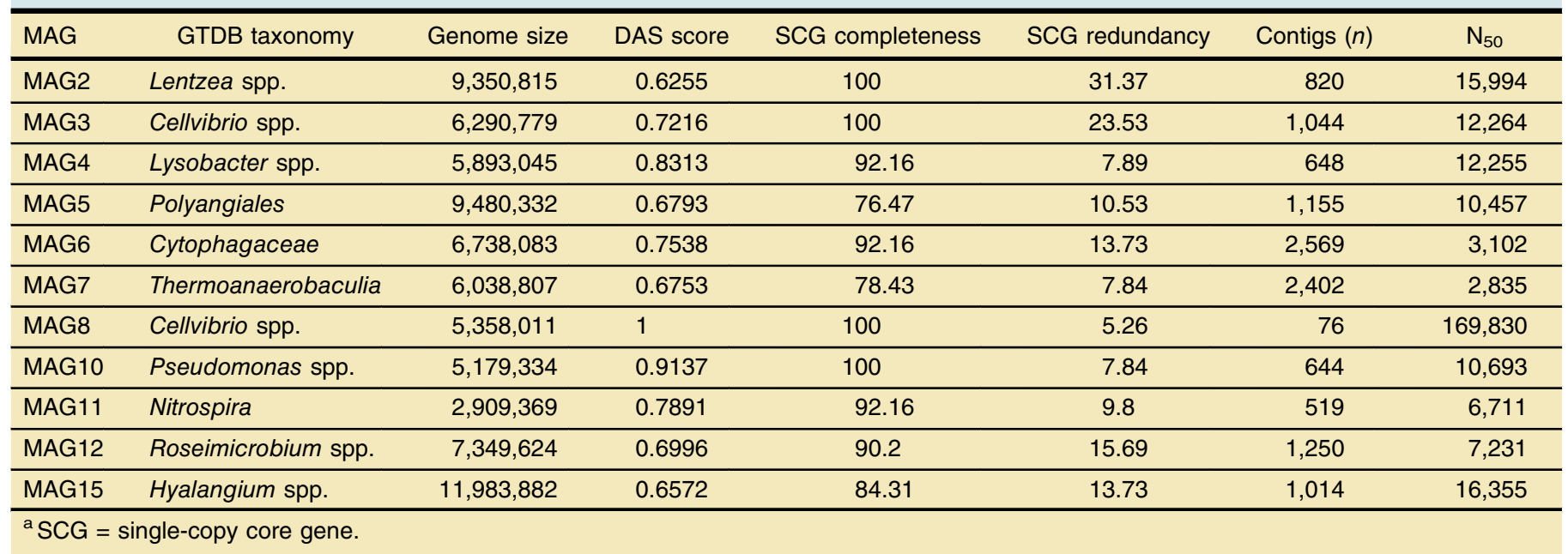


this study was to uncover functional traits of rhizosphere bacteria potentially linked to biochar-stimulated suppression of the soilborne fungal pathogen $F$. oxysporum f. sp. radicis-cucumerinum.

Greenhouse experiments coupled to microbiome analyses revealed that $F$. oxysporum $\mathrm{f}$. sp. radicis-cucumerinum inoculation resulted in a significant reduction in rhizosphere bacterial diversity and a strong shift in bacterial community composition relative to noninoculated plants. However, this phenomenon was highly constrained in biochar-amended plants. We hypothesize that biochar amendment promotes a "buffering effect" that facilitates a stable, more favorable microbial community whose members antagonize F. oxysporum f. sp. radicis-cucumerinum. This buffering may be potentially associated with the capacity of biochar to chemically stabilize the root environment (i.e., through maintaining $\mathrm{pH}$ ) or to provide microniches within its unique carbon skeleton that certain bacterial groups can colonize (Abujabhah et al. 2016; Wang et al. 2017). Previous studies found that biochar increases soil and rhizosphere bacterial community diversity (Cao et al. 2021; Jaiswal et al. 2017; Kolton et al. 2017; Thies et al. 2015), and that this diversity is considered to enhance ecosystem functioning. However, our

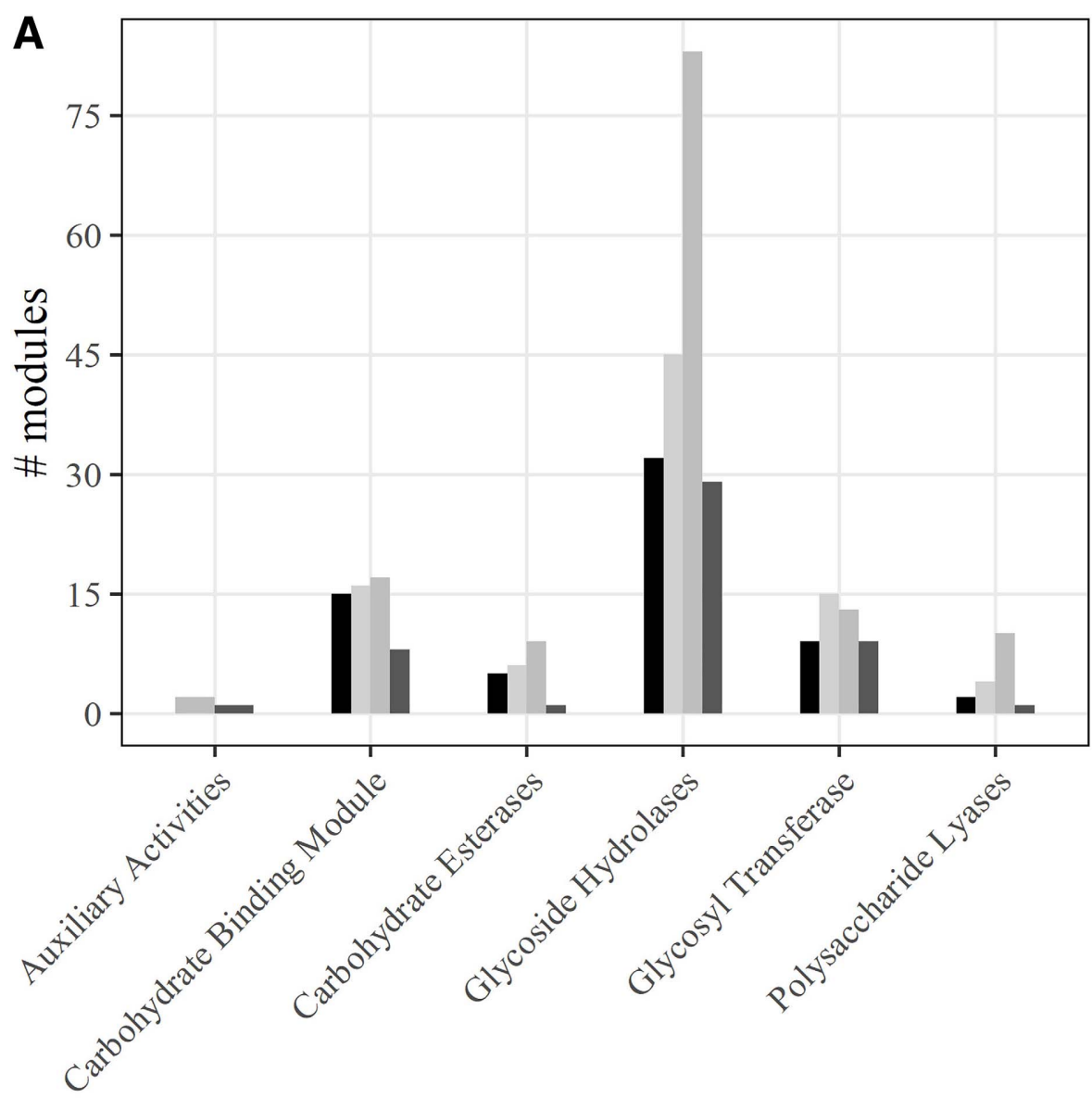

MAG
MAG6 (Cytophagaceae spp.)

MAG15 (Hyalangium spp.)

MAG2 (Lentzea spp.)

MAG5 (Polyangiales)

\section{B}
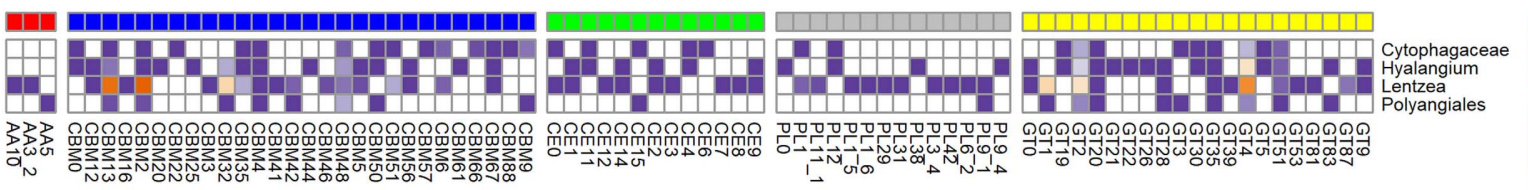

CAZy Family

Auxiliary Activities

Carbohydrate Binding Module Carbohydrate Esterases Glycoside Hydrolases

Glycosyl Transferase

Polysaccharide Lyases

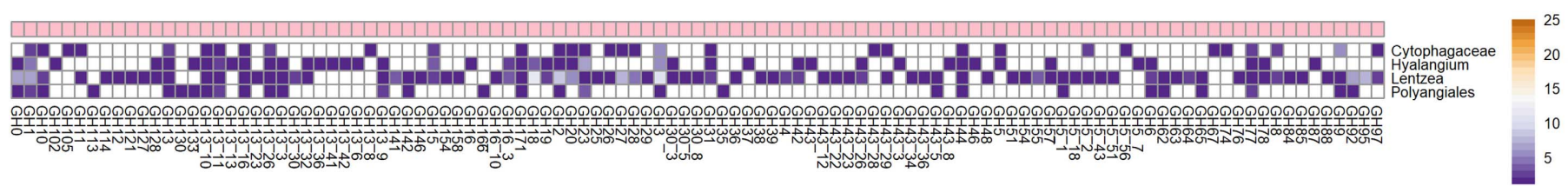

Fig. 6. A, Number of carbohydrate-active enzyme family database (CAZy) modules found within binned metagenomically assembled genomes (MAGs). MAG open reading frames (predicted using Prodigal) were used as input for dbCAN2 meta server, based on DIAMOND (e-value $<1 \mathrm{e}^{-102}$ ) and HMMER (e-value $<1 \mathrm{e}^{-15}$ ). Only modules that were commonly annotated by both tools were included. B, Abundance of specific CAZy families identified within selected MAGs. 
study is unique in the fact that it demonstrates the potential capacity of this increased diversity to facilitate ecosystem functioning in the presence of a soilborne fungal pathogen.

One apparent consequence of the biochar-facilitated buffering effect is the unique array of SM-synthesizing genes harbored by the rhizosphere bacterial community in biochar-amended soil. Specifically, the composition of NRPS or PKS BGCs was higher in the biochar-amended $F$. oxysporum f. sp. radicis-cucumerinum-inoculated samples than in inoculated samples without biochar. SMs assembled by synthases and synthetases encoded by such BGCs are known to mediate a myriad of microbe-microbe and microbe-plant interactions within complex soil and root ecosystems, which include competition, predation, mutuality, and others (Dahlstrom et al. 2020; Sharrar et al. 2020; Tyc et al. 2017). Previous studies determined that plant-root-associated and endosphere microbiomes from naturally suppressive soils harbor specific NRPS- and PKSencoding BGCs (i.e., encoding for iron-chelating siderophores) that potentially antagonize pathogens (Carrión et al. 2019; Tracanna et al. 2021). Furthermore, we previously demonstrated that tomato and lettuce root microbiomes harbor a specific assemblage of bacterial NRPS- or PKS-encoding BGCs, and highlighted characterized and unknown BGCs that may partake in microbe-microbe and microbe-plant interactions in the root environment (Dror et al. 2020). Based on these studies, we targeted specific biocharenriched BGCs that may potentially antagonize $F$. oxysporum $\mathrm{f}$. sp. radicis-cucumerinum.

MAG binning revealed a Lentzea sp. (Pseudonocardiaceae, MAG2), a Hyalangium sp. (Myxococcales, MAG15), and a Cytophagaceae sp. (MAG6) which, based on 16S rRNA gene amplicon sequencing, were found to be highly enriched in the rhizosphere of the biocharamended pots and almost absent from $F$. oxysporum f. sp. radiciscucumerinum-inoculated, biochar-free plants. All three taxonomic groups have been previously identified in soil, while the former two groups are known to encode for different SMs with antibiotic activity (Nadmid et al. 2014; Okanya et al. 2014; Wichner et al. 2017). We propose that SMs produced by these bacteria play a role in reducing $F$. oxysporum f. sp. radicis-cucumerinum in the biocharamended pots. Among binned MAGs, we believe that MAG 2 may

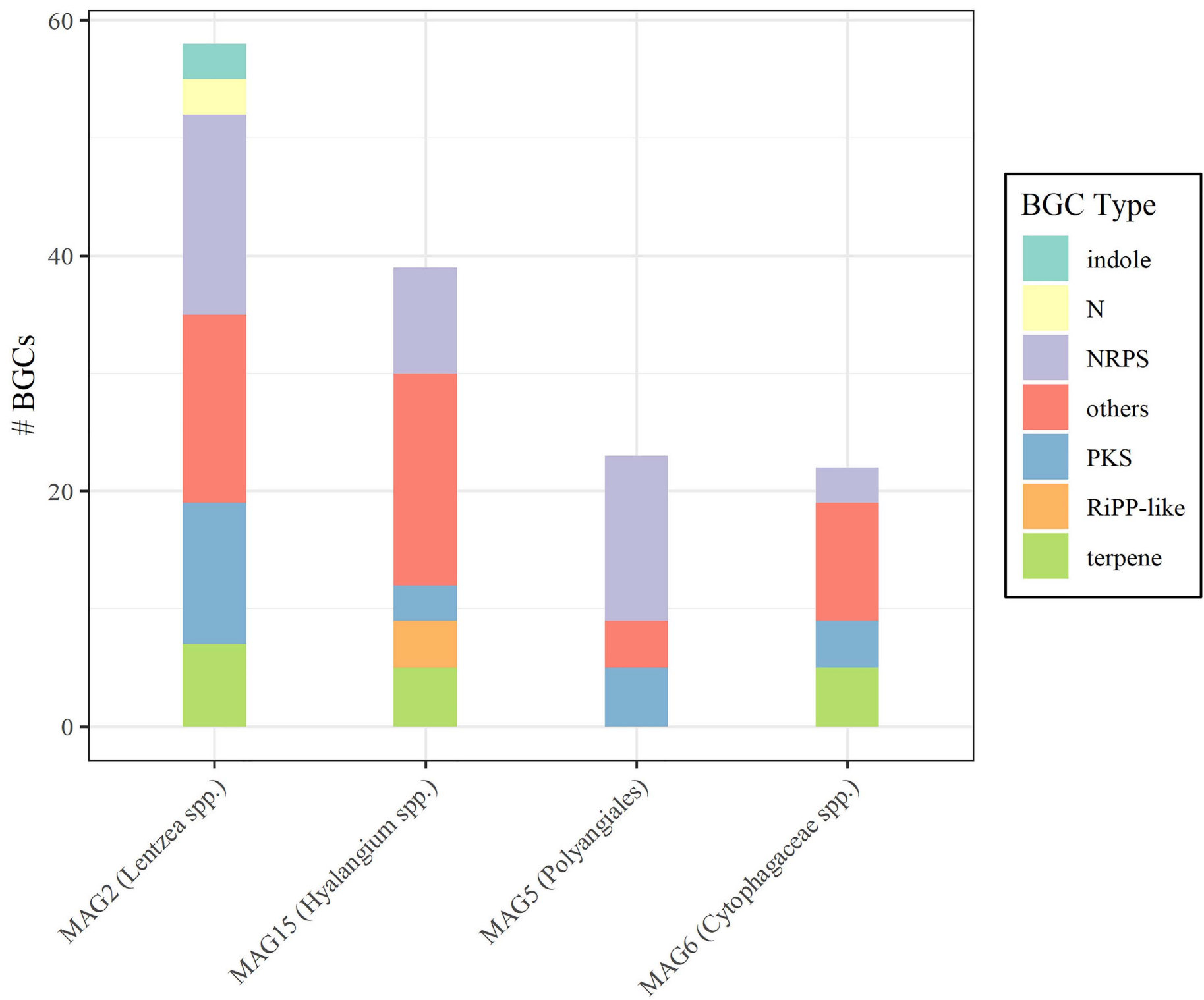

Fig. 7. Distribution of biosynthetic gene cluster (BGC) types in binned metagenomically assembled genomes (MAGs) based on anti-SMASH characterization. Contigs were binned to each MAG using metaBAT2 and CONCOCT, and refined using DAS-Tool. NRPS = nonribosomal peptide synthetase and PKS = polyketide synthase. 
be a key player in the observed biochar-induced $F$. oxysporum f. sp. radicis-cucumerinum inhibition, given the fact that it was highly enriched in the biochar-amended samples, the wealth of unidentified BGC found in its genome, and its chitin-degrading potential. Indeed, two Lentzea isolates strongly antagonized $F$. oxysporum f. sp. radicis-cucumerinum in in vitro assays. Although Lentzea spp. were previously mentioned as endophytes in different crops (Cordero Elvia et al. 2021; Dong et al. 2018), to the best of our knowledge, this is the first demonstration of antifungal activity in this genus. Future studies will aim to identify the exact inhibition mechanism of these isolates, as well as subsequent evaluation of in vitro and in planta antifungal activity

Root-associated bacteria are highly dependent upon enzymes that metabolize plant-associated carbohydrates such as cellulose and hemicellulose (Cole et al. 2017; Levy et al. 2018). We found binned MAGs, and especially MAG2 (Lentzea spp.), to harbor many enzymatic families that are involved in cellulose degradation, most notably CBM-13, which contains galactose-, mannose-, and xylanbinding domains, all prominent components of plant cell walls (Fujimoto 2013). Another example is GH-6, a family with endoglucanase activities involved in cleaving the cellulose polymer into smaller polysaccharides (Henrissat et al. 1989). Moreover, these MAGs also possessed multiple families with chitin degradation and binding functions (i.e., CBM2 and CBM12, GH18, GH19, and GH23) (Nguyen et al. 2018). Because chitin is a major component of fungal cell walls, it may imply that bacteria represented by these MAGs metabolize soil fungi; as, indeed, was found in previously characterized biocontrol agents (Lacombe-Harvey et al. 2018; Seipke et al. 2012; Veliz et al. 2017). The ability of different groups of Actinobacteria (mostly Streptomyces and Micromonospora spp.) to degrade chitin is well established, though evidence regarding chitinase activity in Pseudonocardiaceae species is scarce (Gonzalez-Franco et al. 2003; Yeager et al. 2017).

Overall, we demonstrate that, within the studied soil, biochar facilitates a "buffering effect" that reduces the impact of $F$. oxysporum $\mathrm{f}$. sp. radicis-cucumerinum on rhizosphere microbial diversity and community structure. We suggest that buffering enables persistence of two rhizosphere-associated taxa (Pseudonocardiaceae and

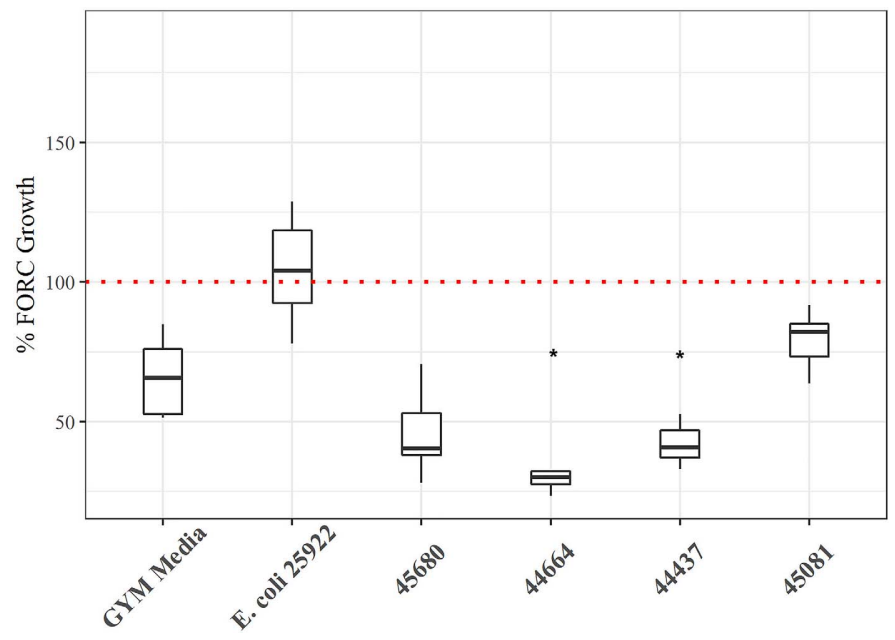

Fig. 8. Comparison of Fusarium oxysporum f. sp. radicis-cucumerinum (FORC) growth (percentage) of the green fluorescent protein antifungal assay after $36 \mathrm{~h}$. GYM media and Escherichia coli ATCC 25922 were used as negative controls. Four commercially available Lentzea strains were tested (Lentzea nigeriaca strain DSM 45680, L. flaviverrucosa strain DSM 44664, L. albida strain DSM 44437 and L. xinjiangensis strain DSM 45081). An asterisk (*) indicates $P$ value $<0.05$ relative to GYM media, analysis of variance, $n=8$.
Myxococcales) that may play a role in the inhibition of $F$. oxysporum f. sp. radicis-cucumerinum; namely, through SM synthesis and degradation of plant- and fungal cell-wall-associated carbohydrates. The integration of MAGs and 16S rRNA gene analysis enabled us to pinpoint four candidates with potential $F$. oxysporum f. sp. radicis-cucumerinum-antagonizing capacity and demonstrate in vitro antifungal activity of closely related strains from culture collections. Future studies will target indigenous strains from the rhizosphere of different host plants in biochar-amended soils and assess their plant growth-promoting ability in planta. In addition, we plan to heterologously express candidate SM-associated BGCs that were found in MAG2 in appropriate host strains and test the in vitro and in planta antagonistic capacity of the heterologously expressing host and of other Lentzea spp. isolates, to understand their role in the complex root environment.

\section{ACKNOWLEDGMENTS}

We thank S. Green for valuable advice and guidance with the next-generation sequencing pipeline; N. Sela and C. L. Gupta for valuable advice regarding the bioinformatic analyses of the sequencing data; M. Cohen for his robust computational resources support; and D. Minz and his lab members, as well as the Cytryn lab members, for valuable feedback and suggestions.

\section{LITERATURE CITED}

Abujabhah, I. S., Bound, S. A., Doyle, R., and Bowman, J. P. 2016. Effects of biochar and compost amendments on soil physico-chemical properties and the total community within a temperate agricultural soil. Appl. Soil Ecol. 98:243-253.

Agegnehu, G., Bass, A. M., Nelson, P. N., and Bird, M. I. 2016. Benefits of biochar, compost and biochar-compost for soil quality, maize yield and greenhouse gas emissions in a tropical agricultural soil. Sci. Total Environ. 543:295-306.

Alneberg, J., Bjarnason, B. S., de Bruijn, I., Schirmer, M., Quick, J., Ijaz, U. Z., Loman, N. J., Andersson, A. F., and Quince, C. 2013. CONCOCT: Clustering contigs on coverage and composition. https://arxiv.org/abs/ 1312.4038

Berendsen, R. L., Pieterse, C. M. J., and Bakker, P. A. H. M. 2012. The rhizosphere microbiome and plant health. Trends Plant Sci. 17:478-486.

Blin, K., Shaw, S., Steinke, K., Villebro, R., Ziemert, N., Lee, S. Y., Medema, M. H., and Weber, T. 2019. AntiSMASH 5.0: Updates to the secondary metabolite genome mining pipeline. Nucleic Acids Res. 47: W81-W87.

Bolger, A. M., Lohse, M., and Usadel, B. 2014. Trimmomatic: A flexible trimmer for Illumina sequence data. Bioinformatics 30:2114-2120.

Bolyen, E., Rideout, J. R., Dillon, M. R., Bokulich, N. A., Abnet, C. C., Al-Ghalith, G. A., Alexander, H., Alm, E. J., Arumugam, M., Asnicar, F., Bai, Y., Bisanz, J. E., Bittinger, K., Brejnrod, A., Brislawn, C. J., Brown, C. T., Callahan, B. J., Caraballo-Rodríguez, A. M., Chase, J., Cope, E. K., Da Silva, R., Diener, C., Dorrestein, P. C., Douglas, G. M., Durall, D. M., Duvallet, C., Edwardson, C. F., Ernst, M., Estaki, M., Fouquier, J., Gauglitz, J. M., Gibbons, S. M., Gibson, D. L., Gonzalez, A., Gorlick, K., Guo, J., Hillmann, B., Holmes, S., Holste, H., Huttenhower, C., Huttley, G. A., Janssen, S., Jarmusch, A. K., Jiang, L., Kaehler, B. D., Kang, K. B., Keefe, C. R., Keim, P., Kelley, S. T., Knights, D., Koester, I., Kosciolek, T., Kreps, J., Langille, M. G. I., Lee, J., Ley, R., Liu, Y.-X., Loftfield, E., Lozupone, C., Maher, M., Marotz, C., Martin, B. D., McDonald, D., McIver, L. J., Melnik, A. V., Metcalf, J. L., Morgan, S. C., Morton, J. T., Naimey, A. T., Navas-Molina, J. A., Nothias, L. F., Orchanian, S. B., Pearson, T., Peoples, S. L., Petras, D., Preuss, M. L., Pruesse, E., Rasmussen, L. B., Rivers, A., Robeson, M. S., II, Rosenthal, P., Segata, N., Shaffer, M., Shiffer, A., Sinha, R., Song, S. J., Spear, J. R., Swafford, A. D., Thompson, L. R., Torres, P. J., Trinh, P., Tripathi, A., Turnbaugh, P. J., Ul-Hasan, S., van der Hooft, J. J. J., Vargas, F., Vázquez-Baeza, Y., Vogtmann, E., von Hippel, M., Walters, W., Wan, Y., Wang, M., Warren, J., Weber, K. C., Williamson, C. H. D., Willis, A. D., Xu, Z. Z., Zaneveld, J. R., Zhang, Y., Zhu, Q., Knight, R., and Caporaso, 
J. G. 2019. Reproducible, interactive, scalable and extensible microbiome data science using QIIME 2. Nat. Biotechnol. 37:852-857.

Bonanomi, G., Lorito, M., Vinale, F., and Woo, S. L. 2018. Organic amendments, beneficial microbes, and soil microbiota: Toward a unified framework for disease suppression. Annu. Rev. Phytopathol. 56:1-20.

Buchfink, B., Xie, C., and Huson, D. H. 2014. Fast and sensitive protein alignment using DIAMOND. Nat. Methods 12:59-60.

Cao, H., Jia, M., Xun, M., Wang, X., Chen, K., and Yang, H. 2021. Nitrogen transformation and microbial community structure varied in apple rhizosphere and rhizoplane soils under biochar amendment. J. Soils Sediments 21:853-868.

Carrión, V. J., Perez-Jaramillo, J., Cordovez, V., Tracanna, V., De Hollander, M., Ruiz-Buck, D., Mendes, L. W., van Ijcken, W. F. J., Goez-Exposito, R., Elsayed, S. S., Mohanraju, P., Arifah, A., van der Oost, J., Paulson, J. N., Mendes, R., van Wezel, G. P., Medema, M. H., and Raaijmakers, J. M. 2019. Pathogen-induced activation of diseasesuppressive functions in the endophytic root microbiome. Science 366: 606-612.

Chaumeil, P. A., Mussig, A. J., Hugenholtz, P., and Parks, D. H. 2020. GTDB-Tk: A toolkit to classify genomes with the genome taxonomy database. Bioinformatics 36:1925-1927.

Chen, S., Qi, G., Ma, G., and Zhao, X. 2020. Biochar amendment controlled bacterial wilt through changing soil chemical properties and microbial community. Microbiol. Res. 231:126373.

Cole, B. J., Feltcher, M. E., Waters, R. J., Wetmore, K. M., Mucyn, T. S., Ryan, E. M., Wang, G., Ul-Hasan, S., McDonald, M., Yoshikuni, Y., Malmstrom, R. R., Deutschbauer, A. M., Dangl, J. L., and Visel, A. 2017. Genome-wide identification of bacterial plant colonization genes. PLoS Biol. 15:e2002860.

Coleman, J. J., Ghosh, S., Okoli, I., and Mylonakis, E. 2011. Antifungal activity of microbial secondary metabolites. PLoS One 6:e25321.

Cordero Elvia, J., de Freitas, R. J., and Germida, J. 2021. Bacterial microbiome associated with the rhizosphere, root interior and aboveground plant organs of wheat and canola at different growth stages. Phytobiomes J. 5:442-451.

Dahlstrom, K. M., McRose, D. L., and Newman, D. K. 2020. Keystone metabolites of crop rhizosphere microbiomes. Curr. Biol. 30:R1131-R1137.

Ding, Y., Liu, Y., Liu, S., Li, Z., Tan, X., Huang, X., Zeng, G., Zhou, L., and Zheng, B. 2016. Biochar to improve soil fertility. A review. Agron. Sustain. Dev. 36:36.

Dong, M., Yang, Z., Cheng, G., Peng, L., Xu, Q., and Xu, J. 2018. Diversity of the bacterial microbiome in the roots of four Saccharum species: $S$. spontaneum, S. robustum, S. barberi, and S. officinarum. Front. Microbiol. 9.

Dror, B., Wang, Z., Brady, S. F., Jurkevitch, E., and Cytryn, E. 2020. Elucidating the diversity and potential function of nonribosomal peptide and polyketide biosynthetic gene clusters in the root microbiome. mSystems 5:e00866-20.

Elad, Y., David, D. R., Harel, Y. M., Borenshtein, M., Ben Kalifa, H., Silber, A., and Graber, E. R. 2010. Induction of systemic resistance in plants by biochar, a soil-applied carbon sequestering agent. Phytopathology 100:913-921.

Esmaeel, Q., Pupin, M., Jacques, P., and Leclère, V. 2017. Nonribosomal peptides and polyketides of Burkholderia: New compounds potentially implicated in biocontrol and pharmaceuticals. Environ. Sci. Pollut. Res. 2530:29794-29807.

Fernandes, C., Gow, N. A. R., and Gonçalves, T. 2016. The importance of subclasses of chitin synthase enzymes with myosin-like domains for the fitness of fungi. Fungal Biol. Rev. 30:1-14.

Fujimoto, Z. 2013. Structure and function of carbohydrate-binding module families 13 and 42 of glycoside hydrolases, comprising a $\beta$-trefoil fold. Biosci. Biotechnol. Biochem. 77:1363-1371.

Gonzalez-Franco, A. C., Deobald, L. A., Spivak, A., and Crawford, D. L. 2003. Actinobacterial chitinase-like enzymes: Profiles of rhizosphere versus non-rhizosphere isolates. Can. J. Microbiol. 49:683-698.

Green, S. J., Venkatramanan, R., and Naqib, A. 2015. Deconstructing the polymerase chain reaction: Understanding and correcting bias associated with primer degeneracies and primer-template mismatches. PLoS One 10: $\mathrm{e} 0128122$.

Henrissat, B., Claeyssens, M., Tomme, P., Lemesle, L., and Mornon, J.-P. 1989. Cellulase families revealed by hydrophobic cluster analysis. Gene 81:83-95.

Huang, W.-k., Ji, H.-1., Gheysen, G., Debode, J., and Kyndt, T. 2015. Biochar-amended potting medium reduces the susceptibility of rice to root-knot nematode infections. BMC Plant Biol. 15:267.
Hyatt, D., Chen, G. L., LoCascio, P. F., Land, M. L., Larimer, F. W., and Hauser, L. J. 2010. Prodigal: Prokaryotic gene recognition and translation initiation site identification. BMC Bioinf. 11:119.

Jaiswal, A., Elad, Y., Paudel, I., Graber, E. R., Cytryn, E., and Frenkel, O. 2017. Linking the belowground microbial composition, diversity and activity to soilborne disease suppression and growth promotion of tomato amended with biochar. Sci. Rep. 7:44382.

Jaiswal, A. K., Alkan, N., Elad, Y., Sela, N., Philosoph, A. M., Graber, E. R., and Frenkel, O. 2020. Molecular insights into biochar-mediated plant growth promotion and systemic resistance in tomato against Fusarium crown and root rot disease. Sci. Rep. 10:13934.

Jaiswal, A. K., Elad, Y., Cytryn, E., Graber, E. R., and Frenkel, O. 2018. Activating biochar by manipulating the bacterial and fungal microbiome through pre-conditioning. New Phytol. 219:363-377.

Kanehisa, M., Sato, Y., and Morishima, K. 2016. BlastKOALA and GhostKOALA: KEGG tools for functional characterization of genome and metagenome sequences. J. Mol. Biol. 428:726-731.

Kang, D. D., Li, F., Kirton, E., Thomas, A., Egan, R., An, H., and Wang, Z. 2019. MetaBAT 2: An adaptive binning algorithm for robust and efficient genome reconstruction from metagenome assemblies. PeerJ 7:e7359.

Kautsar, S. A., Blin, K., Shaw, S., Navarro-Muñoz, J. C., Terlouw, B. R., van der Hooft, J. J. J., van Santen, J. A., Tracanna, V., Duran, H. G. S., Andreu, V. P., Selem-Mojica, N., Alanjary, M., Robinson, S. L., Lund, G., Epstein, S. C., Sisto, A. C., Charkoudian, L. K., Collemare, J., Linington, R. G., Weber, T., and Medema, M. H. 2020. MIBiG 2.0: A repository for biosynthetic gene clusters of known function. Nucleic Acids Res. 48:D454-D458.

Kautsar, S. A., Blin, K., Shaw, S., Weber, T., and Medema, M. H. 2021. BiG-FAM: The biosynthetic gene cluster families database. Nucleic Acids Res. 49:D490-D497.

Klein, E., Katan, J., and Gamliel, A. 2011. Soil suppressiveness to Fusarium disease following organic amendments and solarization. Plant Dis. 95: 1116-1123.

Klein, E., Ofek, M., Katan, J., Minz, D., and Gamliel, A. 2013. Soil suppressiveness to Fusarium disease: Shifts in root microbiome associated with reduction of pathogen root colonization. Phytopathology 103:23-33.

Kolton, M., Graber, E. R., Tsehansky, L., Elad, Y., and Cytryn, E. 2017. Biochar-stimulated plant performance is strongly linked to microbial diversity and metabolic potential in the rhizosphere. New Phytol. 213: 1393-1404.

Lacombe-Harvey, M.-È., Brzezinski, R., and Beaulieu, C. 2018. Chitinolytic functions in actinobacteria: Ecology, enzymes, and evolution. Appl. Microbiol. Biotechnol. 102:7219-7230.

Langmead, B., and Salzberg, S. L. 2012. Fast gapped-read alignment with Bowtie 2. Nat. Methods 9:357-359.

Levy, A., Salas Gonzalez, I., Mittelviefhaus, M., Clingenpeel, S., Herrera Paredes, S., Miao, J., Wang, K., Devescovi, G., Stillman, K., Monteiro, F., Alvarez, B. R., Lundberg, D. S., Lu, T.-Y., Lebeis, S., Jin, Z., McDonald, M., Klein, A. P., Feltcher, M. E., Rio, T. G., Grant, S. R., Doty, S. L., Ley, R. E., Zhao, B., Venturi, V., Pelletier, D. A., Vorholt, J. A., Tringe, S. G., Woyke, T., and Dangl, J. L. 2018. Genomic features of bacterial adaptation to plants. Nat. Genet. 50:138-150.

Li, W., and Godzik, A. 2006. Cd-hit: A fast program for clustering and comparing large sets of protein or nucleotide sequences. Bioinformatics 22:1658-1659.

Love, M., Anders, S., and Huber, W. 2014. Differential analysis of count data-The DESeq2 package. https://data.broadinstitute.org/snowman/ofer/ RNAseq/DESeq2\%20guide.pdf

Mallick, H., Rahnavard, A., McIver, L. J., Ma, S., Zhang, Y., Nguyen, L. H., Tickle, T. L., Weingart, G., Ren, B., Schwager, E. H., Chatterjee, S., Thompson, K. N., Wilkinson, J. E., Subramanian, A., Lu, Y., Waldron, L., Paulson, J. N., Franzosa, E. A., Bravo, C., and Huttenhower, C. 2021. Multivariable association discovery in population-scale meta-omics studies. Biorxiv.

Mikheenko, A., Saveliev, V., and Gurevich, A. 2016. MetaQUAST: Evaluation of metagenome assemblies. Bioinformatics 32:1088-1090.

Moonsamy, P. V., Williams, T., Bonella, P., Holcomb, C. L., Höglund, B. N., Hillman, G., Goodridge, D., Turenchalk, G. S., Blake, L. A., Daigle, D. A., Simen, B. B., Hamilton, A., May, A. P., and Erlich, H. A. 2013. High throughput HLA genotyping using 454 sequencing and the Fluidigm Access Array ${ }^{\mathrm{TM}}$ system for simplified amplicon library preparation. Tissue Antigens 81:141-149. 
Nadmid, S., Plaza, A., Lauro, G., Garcia, R., Bifulco, G., and Müller, R. 2014. Hyalachelins A-C, unusual siderophores isolated from the terrestrial myxobacterium Hyalangium minutum. Org. Lett. 16:4130-4133.

Navarro-Muñoz, J. C., Selem-Mojica, N., Mullowney, M. W., Kautsar, S. A., Tryon, J. H., Parkinson, E. I., De Los Santos, E. L. C., Yeong, M., Cruz-Morales, P., Abubucker, S., Roeters, A., Lokhorst, W., Fernandez-Guerra, A., Cappelini, L. T. D., Goering, A. W., Thomson, R. J., Metcalf, W. W., Kelleher, N. L., Barona-Gomez, F., and Medema, M. H. 2020. A computational framework to explore large-scale biosynthetic diversity. Nat. Chem. Biol. 16:60-68.

Newman, D. J., and Cragg, G. M. 2016. Natural products as sources of new drugs from 1981 to 2014. J. Nat. Prod. 79:629-661.

Nguyen, S. T. C., Freund, H. L., Kasanjian, J., and Berlemont, R. 2018. Function, distribution, and annotation of characterized cellulases, xylanases, and chitinases from CAZy. Appl. Microbiol. Biotechnol. 102: 1629-1637.

Nurk, S., Meleshko, D., Korobeynikov, A., and Pevzner, P. A. 2017. MetaSPAdes: A new versatile metagenomic assembler. Genome Res. 27: 824-834.

Okanya, P. W., Mohr, K. I., Gerth, K., Kessler, W., Jansen, R., Stadler, M., and Müller, R. 2014. Hyafurones, hyapyrrolines, and hyapyrones: Polyketides from Hyalangium minutum. J. Nat. Prod. 77:1420-1429.

Parks, D. H., Imelfort, M., Skennerton, C. T., Hugenholtz, P., and Tyson, G. W. 2015. CheckM: Assessing the quality of microbial genomes recovered from isolates, single cells, and metagenomes. Genome Res. 25: 1043-1055.

Pruesse, E., Peplies, J., and Glöckner, F. O. 2012. SINA: Accurate highthroughput multiple sequence alignment of ribosomal RNA genes. Bioinformatics 28:1823-1829.

Seipke, R. F., Kaltenpoth, M., and Hutchings, M. I. 2012. Streptomyces as symbionts: An emerging and widespread theme? FEMS Microbiol. Rev. 36:862-876.

Sharrar, A. M., Crits-Christoph, A., Méheust, R., Diamond, S., Starr, E. P., and Banfield, J. F. 2020. Bacterial secondary metabolite biosynthetic potential in soil varies with phylum, depth, and vegetation type. MBio 11: e00416-20.

Sieber, C. M. K., Probst, A. J., Sharrar, A., Thomas, B. C., Hess, M., Tringe, S. G., and Banfield, J. F. 2018. Recovery of genomes from metagenomes via a dereplication, aggregation and scoring strategy. Nat. Microbiol. 3: 836-843.
Thies, J. E., Rillig, M. C., and Graber, E. R. 2015. Biochar effects on the abundance, activity and diversity of the soil biota. Pages 327-389 in: Biochar for Environmental Management: Science, Technology and Implementation, 2nd Ed. J. Lehmann and S. Joseph, eds. Routledge, London, U.K.

Tracanna, V., Ossowicki, A., Petrus, M. L. C., Overduin, S., Terlouw, B. R., Lund, G., Robinson, S. L., Warris, S., Schijlen, E. G. W. M., van Wezel, G. P., Raaijmakers, J. M., Garbeva, P., and Medema, M. H. 2021. Dissecting disease-suppressive rhizosphere microbiomes by functional amplicon sequencing and 10× metagenomics. mSystems 6:e01116-20.

Trivedi, P., Leach, J. E., Tringe, S. G., Sa, T., and Singh, B. K. 2020. Plant-microbiome interactions: From community assembly to plant health. Nat. Rev. Microbiol. 18:607-621.

Tyc, O., Song, C., Dickschat, J. S., Vos, M., and Garbeva, P. 2017. The ecological role of volatile and soluble secondary metabolites produced by soil bacteria. Trends Microbiol. 25:280-292.

Vejan, P., Abdullah, R., Khadiran, T., Ismail, S., and Nasrulhaq Boyce, A. 2016. Role of plant growth promoting rhizobacteria in agricultural sustainability-A review. Molecules 21:573.

Veliz, E. A., Martínez-Hidalgo, P., and Hirsch, A. M. 2017. Chitinaseproducing bacteria and their role in biocontrol. AIMS Microbiol. 3:689.

Wang, D., Fonte, S. J., Parikh, S. J., Six, J., and Scow, K. M. 2017. Biochar additions can enhance soil structure and the physical stabilization of $\mathrm{C}$ in aggregates. Geoderma 303:110-117.

Wang, G., Govinden, R., Chenia, H. Y., Ma, Y., Guo, D., and Ren, G. 2019 Suppression of Phytophthora blight of pepper by biochar amendment is associated with improved soil bacterial properties. Biol. Fertil. Soils 55: 813-824.

Wichner, D., Idris, H., Houssen, W. E., McEwan, A. R., Bull, A. T., Asenjo, J. A., Goodfellow, M., Jaspars, M., Ebel, R., and Rateb, M. E. 2017. Isolation and anti-HIV-1 integrase activity of lentzeosides A-F from extremotolerant Lentzea sp. H45, a strain isolated from a high-altitude Atacama Desert soil. J. Antibiot. 70:448-453.

Yeager, C. M., Gallegos-Graves, L. V., Dunbar, J., Hesse, C. N., Daligault, H., and Kuske, C. R. 2017. Polysaccharide degradation capability of Actinomycetales soil isolates from a semiarid grassland of the Colorado Plateau. Appl. Environ. Microbiol. 83:e03020-16.

Zhang, H., Yohe, T., Huang, L., Entwistle, S., Wu, P., Yang, Z., Busk, P. K., $\mathrm{Xu}, \mathrm{Y}$., and Yin, Y. 2018. DbCAN2: A meta server for automated carbohydrate-active enzyme annotation. Nucleic Acids Res. 46:W95-W101. 